\title{
The Endometriosis Impact Questionnaire (EIQ): a tool to measure the long-term impact of endometriosis on different aspects of women's lives
}

\author{
Maryam Moradi ${ }^{1 *}$ (D), Melissa Parker ${ }^{2}$, Anne Sneddon ${ }^{3}$, Violeta Lopez ${ }^{4}$ and David Ellwood ${ }^{3}$
}

\begin{abstract}
Background: Endometriosis is a chronic disease impacting on many aspects of a woman's life. Because of the chronic and recurring nature, many of the impacts of endometriosis could be missed using existing questionnaires which focus on recent events. Therefore, a questionnaire with a long-term perspective is necessary. This study aimed to develop and evaluate a questionnaire to measure the long-term impact of endometriosis on different aspects of women's lives.

Methods: Through a methodological design, phase 1 was qualitative and phase 2 was a cross-sectional study. The original 100 EIQ items were developed based on results from an earlier qualitative study and literature review. Through a process of assessing face and content validity this was reduced to 66 items. The psychometric properties of the final 63 item ElQ were evaluated through a web-based survey with data from 423 responders with a selfreported surgically-diagnosed endometriosis.

Results: Participants were aged 16-58 years. Exploratory factor analysis of a 66-item EIQ was established with 423 responders. The final 63-item EIQ contained six dimensions including: 33-item physical-psychosocial; 3-item fertility; 7-item sexual; 11-item employment; 6-item educational; and 3-item lifestyle. Cronbach's alpha of 0.99 for the whole 63-item EIQ, and 0.84 to 0.98 for the dimensions suggests a very good reliability. High positive correlations between the EIQ and the EHP-5 (altered recall period) indicated good evidence of concurrent validity. High intra-class correlations indicated very good test-retest reliability.

Conclusions: The EIQ, as a disease-specific questionnaire, could be used to provide a better understanding of the impact of endometriosis on different aspects of life, to better meet the needs of women. We recommend additional studies to establish validity evidence for the EIQ, including studies in other countries and languages.
\end{abstract}

Keywords: Endometriosis, questionnaire, psychometrics, reliability, validation study, quality of life

\section{Background}

Endometriosis is a high prevalence condition causing chronic pelvic pain, and the third leading cause of gynaecological hospitalization in the United States with high rates of hysterectomy [1]. Endometriosis requires lifelong management [2] and treatment must be individualized, taking into account the entire clinical problem,

\footnotetext{
* Correspondence: moradim@mums.ac.ir; maryam.moradi.fu@gmail.com ${ }^{1}$ Nursing and Midwifery Care Research Center, Mashhad University of Medical Sciences, Mashhad, Iran

Full list of author information is available at the end of the article
}

including disease impact and effects of treatment on quality of life (QoL) [3]. The most widely used instruments are the generic Health-Related Quality of Life (HRQoL) questionnaire including the Short Form-36 version (SF-36) [4, 5], the short version of the World Health Organization QoL (WHOQOL-BREF) [6, 7], and the EuroQol-5D [8]. However, the general HRQoL questionnaires do not consider unique variables related to endometriosis such as infertility [9] and the impact of symptoms other than pain. There are some specific questionnaires including Endometriosis Health Profile-30

(c) The Author(s). 2019 Open Access This article is distributed under the terms of the Creative Commons Attribution 4.0 International License (http://creativecommons.org/licenses/by/4.0/), which permits unrestricted use, distribution, and reproduction in any medium, provided you give appropriate credit to the original author(s) and the source, provide a link to the Creative Commons license, and indicate if changes were made. The Creative Commons Public Domain Dedication waiver (http://creativecommons.org/publicdomain/zero/1.0/) applies to the data made available in this article, unless otherwise stated. 
(EHP-30) [10] and its subset, the EHP-5 [11], Endometriosis Treatment Satisfaction Questionnaire (ETSQ) [12], daily electronic Endometriosis Pain and Bleeding Diary (EPBD) [13], and 'Patient-Centred Endometriosis' questionnaire of Endo Care Questionnaire (ECQ) [14] but the EHP-30 is currently the disease-specific questionnaire to measure the HRQoL with the strongest validity evidence [9].

Published studies assessed the impact of endometriosis on pain using the VAS, depression using the BDI or HAM-D, anxiety using STAI or HAM-A [7], work impairment using WPAI $[5,8]$, sexual satisfaction using GRISS [6] and the GSSI [15], and sexual function using the FSDS or FSFI [16], and DSFI [15]. There is limited research on the psychological impacts of endometriosis except for depression/anxiety, work, education, social life, and lifestyle.

Existing tools only asses a subset of QOL indicators, and measure disease impact with a perspective of four weeks or less. Due to the chronic, recurring nature of endometriosis, many disease impacts could be missed, so a multi-dimensional questionnaire with a longer-term perspective is necessary to provide a better understanding. Women's perceptions of the impact of endometriosis have been explored through our earlier qualitative study [17]. We have now developed and evaluated the psychometric properties of a questionnaire to measure the longer-term impact of endometriosis on different aspects of women's lives.

\section{Methods}

The Endometriosis Impact Questionnaire (EIQ) is a self-report questionnaire which asks women how endometriosis has affected their lives over the three recall periods including 'last 12 months', ' 1 to 5 years ago' and 'more than 5 years ago'. Categorical responses for all EIQ items are ranked using a 5 point Likert scale including: $0=$ Not at all, $1=$ A little, $2=$ Somewhat, $3=$ Quite a lot, $4=$ Very much and $9=$ Not applicable. Each item contributes equally and higher scores indicate a greater impact. The EIQ was developed and a psychometric evaluation conducted, using face, content, construct (factor analysis), concurrent validity, and reliability (internal consistency and test-retest reliability). The study used a methodological design which involved the development and evaluation of data collection instruments, scales or techniques [18]. To evaluate construct and concurrent validity and reliability, a cross-sectional study was conducted via a web-based survey. The development process is illustrated in Figure 1. All data were analyzed using SPSS version 20 , and a probability values of $\mathrm{p}<0.05$ were considered to be statistically significant.

\section{Developing the items of the EIQ}

The original 100 EIQ items were developed from a qualitative study [17] and from a systematic literature review. Eight steps on scale development [19], and the criteria for selecting items [20], were followed. The readability of the EIQ based on the Fog index [21] and 'Readability Formulas' [22] were used. In addition, endometriosis patients and experts were asked to evaluate readability of items [21].

\section{Evaluating the psychometric properties Validity}

The adequacy of a scale as a measure of a specific variable is an issue of validity [19]. The initial 100-item EIQ was evaluated to delete repeated items or those which related to only a few women from the focus groups discussions [17], so it was reduced to 89 items.

\section{Face validity}

Feedback was sought from 12 patients and 14 health professionals with expertise in endometriosis, questionnaires development, chronic disease, and psychology. They reviewed the 89-item EIQ and answered three open questions; 1. Does this appear to be a good measure of the impact of endometriosis? 2. List any areas pertinent to the impact of that are not covered 3. Share with us your feedback or any other comments to improve the EIQ.

\section{Content validity}

For the content validity index (CVI) [21], we asked the same 12 patients and 14 health professionals to review the 89-item EIQ and rate the items based on 'Relevance', 'Clarity' and 'Simplicity' on a four-point scale. The CVI was measured as a percentage of the items rated as 3 or $4[23,24]$. Item-level content validity index (I-CVI) was computed as the number of experts giving a rating of either 3 or 4, divided by the total number of experts [25]. A CVI or S-CVI of 0.80 was considered as indicating acceptability [23]. Following these steps the EIQ was reduced to 66 items.

\section{Construct validity}

The initial EIQ had randomly-ordered items to avoid hypothesised factor structure. But considering the number of items and the three recall periods, random-ordering made the EIQ difficult and time consuming to complete. Some experts suggested arranging the items in logical groups rather than having the items all mixed up, to make it easier to complete by responders. Therefore, the initial EIQ with randomly-ordered items was divided into logical groups based on categories which emerged from results of an earlier 


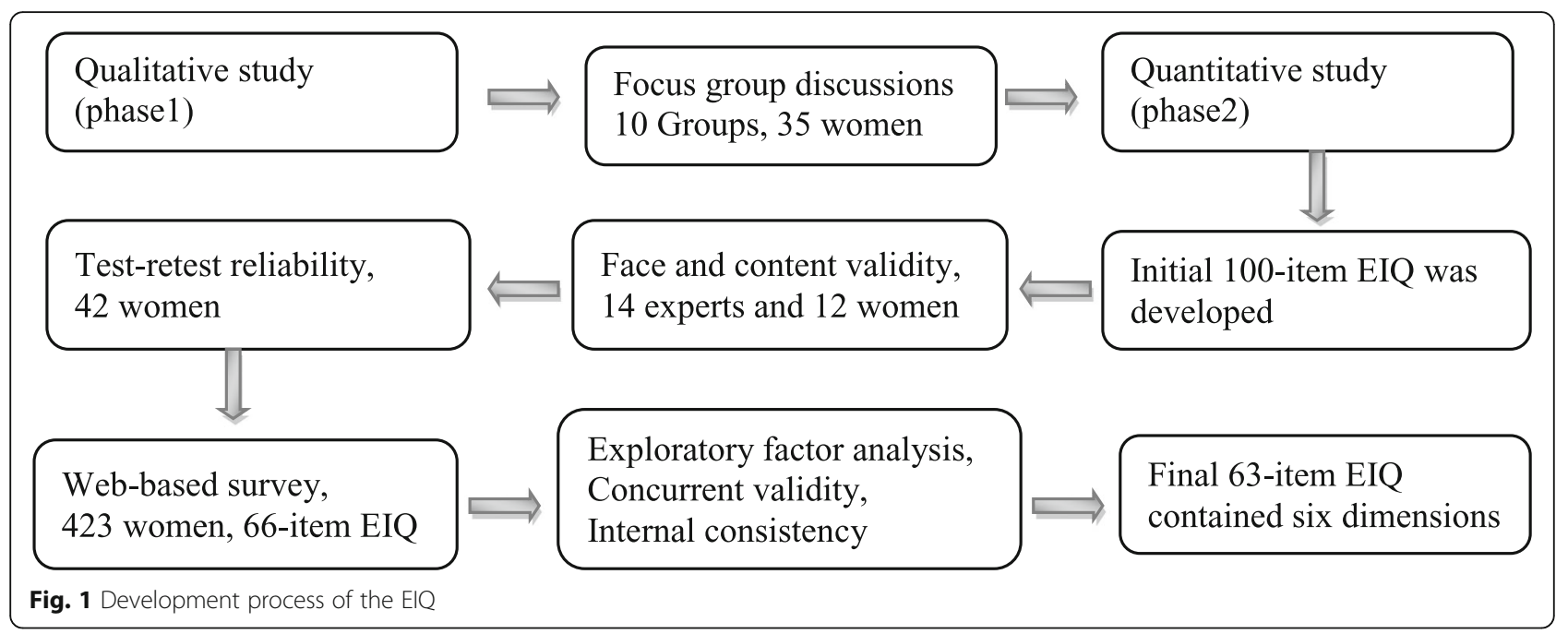

qualitative study [17], but the main categorizing of the EIQ was made based on exploratory factor analysis. The 66-item EIQ was then subjected to exploratory factor analysis to assess construct validity [26]. The commonly used method of principal component analysis and varimax rotation was used [27]. For this study, the acceptable level for factor loading was equal to or greater than 0.40 [28], and eigenvalues greater than one [27] were considered. The required sample size was estimated at 350 to 400 to have subject-to-variable ratio of 5:1, which identified as adequate in most cases [26].

\section{Concurrent validity}

There is no comparable questionnaire with a long-term perspective so to assess concurrent validity the EHP-5 [11] was chosen and the recall period changed from the 'last 4 weeks' to 'last 12 months'.

\section{Reliability}

Two frequently used indicators of a scale's reliability, including internal consistency (Cronbach's alpha) and stability (Pearson correlation coefficient (r), test-retest reliability) were evaluated [26].

\section{Internal consisten $3 c y$ reliability}

Strong item-total correlations were identified as above 0.30 and inter-item correlations as ranging 0.30-0.70 [29]. In this study, a Cronbach's alpha $\geq 0.7$ was considered satisfactory and a corrected item-to-total correlation of at least 0.3 was considered as acceptable.

\section{Test-retest reliability}

To determine test-retest reliability, two copies of the final version were posted to 70 patients, who completed a first copy on the day that they received it, and a second copy after two weeks. Statistical differences between the two scores were assessed.

\section{Sample and setting}

Convenience and snowball sampling were used to recruit a sufficiently large number of accessible participants, with an emphasis on those residing in Australia. Inclusion criteria were self-reported surgically-diagnosed endometriosis and ability to understand English. A web-based survey was conducted and recruitment was through different strategies from secondary or tertiary care levels, as well as from the general community. The EIQ-link was widely advertised via flyers disseminated or posted. Many groups and people (like endometriosis centres and endometriosis support groups) were asked to assist by forwarding an invitation email to their databases and/or by putting flyers in their centres or on their website/Facebook pages.

\section{Pilot study}

A pilot study was conducted for the EIQ paper version and then for the EIQ online version. The EIQ paper version was finalized and pilot tested with eight patients in July 2013 and all responders provided positive feedback, stating that "It is comprehensive" and "It is clear". The online EIQ was developed using ANU Polling Online (APOLLO) in August 2013 (Link: https://apollo. anu.edu.au/default.asp?pid=7700) and was pilot tested with four patients in September 2013. Feedback was generally positive stating that "It worked fine" and "The instructions are very clear".

\section{Results}

\section{EIQ item generation}

The first draft of the EIQ included 100 items which reduced to 89 . Face validity, content validity and further 
revisions resulted in a decrease to 66 items, and this version was used to assess factor analysis, concurrent validity, and test-retest reliability. Through factor analysis, three items were deleted and 63 items formed the final EIQ (Additional file 1).

\section{Demographic and clinical characteristics of responders}

A total of 484 responders completed the final 63-item version between September 2013 and February 2014. One was excluded for providing incorrect completion; all 483 remaining questionnaires were fully completed. A further 60 responders were excluded as they did not have surgically-diagnosed endometriosis. Data from the remaining 423 responders were used to assess the psychometric properties of the EIQ. Demographic and clinical characteristics are provided in Table 1.

\section{Readability of the EIQ}

Gunning Fog Index was 8.7 for the 66-item EIQ and 8.6 for the 63-item EIQ, both of which are considered as 'fairly easy to read'. Based on seven readability formulae the EIQ was scored as grade level 6, which means a standard/average reading level suitable for readers aged 10-11 years (fifth and sixth graders).

\section{Face validity}

Most believed that the EIQ was 'comprehensive' and a 'good' measure of the impact of endometriosis. Only one patient and four of the experts reported that the 89-item EIQ was too long and suggested reviewing it for redundant items.

\section{Content validity}

Content validity of the 89-item EIQ was based on seven out of 14 experts and six out of 12 patient's ratings. The inter-rater agreements were 0.84 (experts) and 0.93 (patients). S-CVI and I-CVIs indicated acceptable content validity for both the EIQ and its items. Although, based on I-CVIs only two out of 89 items required deletion or change, a further 21 items were deleted to shorten to 66 items; these were items that overlapped, or had a low score on clarity or simplicity.

\section{Construct validity}

A sample size of 423 was adequate for factor analysis based on a Kaiser-Meyer-Olkin (KMO) test result of more than 0.9 and a Bartlett's test of sphericity that was significant $(\mathrm{p}<0.01)$. An inspection of the scree plot revealed a break after six or seven factors. All items with a factor loading of 0.4 and above were retained. The results from the factor analysis of the EIQ and each of three recall periods including 'last 12 months, ' 1 to 5 years ago' and 'more than 5 years ago' were consistent to support having six separate factors for physical-psychosocial, fertility, sexual, employment, educational and lifestyle. The exception was that in the 'more than 5 years ago' period some of the physical items were loaded into a separate factor. However, to have consistent factor dimensions, it was decided to include the physical items into the physical-psychosocial dimension. Factor analysis with six factors explained 58.14, 53.84, 52.86, and 46.09 of the total variance in recall period of 'last 12 months,' ' 1 to 5 years ago,' 'more than 5 years ago', and the total EIQ respectively. Three items were removed from the 66-item EIQ because they did not reach a 0.4 factor loading. In comparison with the primary EIQ categorizing, factor analysis identified a new dimension which was called fertility, combined the physical, psychological and social items into one factor called physical-psychosocial, and transferred some items between dimensions.

\section{Final EIQ}

The final EIQ with 63 items had six dimensions: (1) physical-psychosocial - 33 items (consisting of physical 13 items, psychological- 16 items and social impact -4 items); (2) fertility - 3 items; (3) sexual - 7 items; (4) employment - 11 items; (5) educational - 6 items; and (6) lifestyle - 3 items (Additional file 1).

\section{Concurrent validity}

There were statistically significant high positive correlations $(r=0.66-0.80,(\mathrm{n}=423), \mathrm{p}<0.01)$ between the last 12 months' of the EIQ and the EHP-5 (Table 2), indicating that patients who experienced a greater impact (higher EIQ score) had worse health-related quality of life (higher score from the EHP-5). Therefore, the recall period of 'last 12 months' for the EIQ, had high concurrent validity or very good correlation with the EHP-5. Correlations were good $(r=0.40-0.58)$ when the EHP-5 was compared with the ' 1 to 5 years ago' period of the EIQ, and medium or low ( $r=0.17-0.45)$ when compared with the 'more than 5 years ago' period of the EIQ, except for sexual dimension and intercourse module, which was good at a level of $\mathrm{p}=0.45$.

\section{EIQ Scoring}

The score for each dimension at each recall period was the sum of all applicable items divided by the maximum score, rescaled to $0-100$. The total score for each dimension was calculated as a mean of the three recall periods. If responders skipped a dimension or recall period, because they were not applicable to them, a score for that dimension or recall period could not be calculated.

An SPSS code was provided to score the EIQ. The formula for scoring the EIQ and its dimensions on a scale from 0-100 was the sum of the scores of the applicable items multiplied 100/the maximum score of the applicable items, which was the number of applicable items $x$ 
Table 1 Demographic and clinical characteristics of women with endometriosis $(n=423)$

\begin{tabular}{|c|c|c|}
\hline Characteristics & & $n(\%)$ \\
\hline $\mathrm{Age}^{\mathrm{a}}$ (years) & & $\begin{array}{l}\text { 32.64 } 8.38 \\
\text { (Range: } 16-58 \text { ) }\end{array}$ \\
\hline \multirow[t]{3}{*}{ Age groups } & Aged 16-24 & $75(17.73)$ \\
\hline & Aged 25-34 & $186(43.97)$ \\
\hline & $\begin{array}{l}\text { Aged } 35 \text { and } \\
\text { above }\end{array}$ & $162(38.30)$ \\
\hline \multirow[t]{2}{*}{ Country of birth } & Australia & $313(74.00)$ \\
\hline & Other & $110(26.00)$ \\
\hline \multirow[t]{2}{*}{ Country at time of doing the EIQ } & Australia & $351(82.98)$ \\
\hline & Other & $72(17.02)$ \\
\hline \multirow[t]{2}{*}{ Language is spoken at home } & English & 418 (98.82) \\
\hline & Other & $5(1.18)$ \\
\hline \multirow[t]{6}{*}{ Marital status } & Married & $187(44.21)$ \\
\hline & In a relationship & $129(30.50)$ \\
\hline & Never married & $48(11.35)$ \\
\hline & Single & $45(10.64)$ \\
\hline & $\begin{array}{l}\text { Separated/ } \\
\text { Divorced }\end{array}$ & $13(3.07)$ \\
\hline & Widowed & $1(0.24)$ \\
\hline \multirow[t]{8}{*}{ Educational level } & $\begin{array}{l}\text { Primary or high } \\
\text { school }\end{array}$ & $14(3.31)$ \\
\hline & $\begin{array}{l}\text { Lower secondary } \\
\text { school }\end{array}$ & $22(5.20)$ \\
\hline & $\begin{array}{l}\text { Upper secondary } \\
\text { school }\end{array}$ & $47(11.11)$ \\
\hline & $\begin{array}{l}\text { Vocational } \\
\text { (e.g. TAFE) }\end{array}$ & $79(18.68)$ \\
\hline & $\begin{array}{l}\text { Some college/ } \\
\text { university }\end{array}$ & $42(9.93)$ \\
\hline & $\begin{array}{l}\text { Tertiary, } \\
\text { undergraduate }\end{array}$ & $131(30.97)$ \\
\hline & $\begin{array}{l}\text { Tertiary, } \\
\text { postgraduate }\end{array}$ & $76(17.97)$ \\
\hline & Other & $12(2.84)$ \\
\hline \multirow[t]{8}{*}{ Employment $^{\mathrm{b}}$} & Not employed & $43(10.17)$ \\
\hline & $\begin{array}{l}\text { Paid work, full } \\
\text { time }\end{array}$ & $200(47.28)$ \\
\hline & $\begin{array}{l}\text { Paid work, part } \\
\text { time }\end{array}$ & $119(28.13)$ \\
\hline & Home duties & $47(11.11)$ \\
\hline & Student, full time & $30(7.09)$ \\
\hline & Student, part time & $22(5.20)$ \\
\hline & Retired & $3(0.71)$ \\
\hline & Other & $38(8.98)$ \\
\hline \multirow[t]{3}{*}{ Pregnancy history ${ }^{\mathrm{b}}$} & Never pregnant & $237(56.03)$ \\
\hline & $\begin{array}{l}\text { One or more } \\
\text { children }\end{array}$ & $126(29.79)$ \\
\hline & $\begin{array}{l}\text { Miscarriage or } \\
\text { stillbirth }\end{array}$ & $64(15.13)$ \\
\hline
\end{tabular}

Table 1 Demographic and clinical characteristics of women with endometriosis ( $n=423)$ (Continued)

\begin{tabular}{|c|c|c|}
\hline Characteristics & & $n(\%)$ \\
\hline & $\begin{array}{l}\text { Currently } \\
\text { pregnant }\end{array}$ & $10(2.36)$ \\
\hline \multirow[t]{3}{*}{ Delayed fertility } & $\begin{array}{l}\text { Not applicable } \\
\text { (never tried) }\end{array}$ & $194(45.86)$ \\
\hline & No & 69 (16.31) \\
\hline & Yes & $160(37.83)$ \\
\hline Age at onset of symptoms ${ }^{a}$ (years) & & $\begin{array}{l}16.35 \pm 5.21 \\
\text { (Range: } 8-42 \text { ) }\end{array}$ \\
\hline Age at first visit to doctor ${ }^{a}$ (years) & & $\begin{array}{l}\text { 19.70 } \pm 6.49 \\
\text { (Range: } 9-43 \text { ) }\end{array}$ \\
\hline Age at diagnosis ${ }^{a}$ (years) & & $\begin{array}{l}24.65 \pm 6.58 \\
\text { (Range: } 12-43 \text { ) }\end{array}$ \\
\hline Delay in diagnosis ${ }^{a}$ (years) & & $\begin{array}{l}8.31 \pm 6.58 \\
\text { (Range: } 0-28)\end{array}$ \\
\hline \multirow{10}{*}{$\begin{array}{l}\text { Endometriosis-related symptoms } \\
\text { (life time). }\end{array}$} & Period pain & $420(99.29)$ \\
\hline & Fatigue & 397 (93.85) \\
\hline & Bloating & $386(91.25)$ \\
\hline & $\begin{array}{l}\text { Pelvic pain not } \\
\text { related to periods }\end{array}$ & $382(90.31)$ \\
\hline & $\begin{array}{l}\text { Ovulation/mid } \\
\text { cycle pain }\end{array}$ & $377(89.13)$ \\
\hline & $\begin{array}{l}\text { Pain during/after } \\
\text { sex }\end{array}$ & 354 (83.69) \\
\hline & Heavy bleeding & $345(81.56)$ \\
\hline & Irregular bleeding & $271(64.07)$ \\
\hline & Delayed fertility & $158(37.35)$ \\
\hline & Other & $91(21.51)$ \\
\hline \multirow{10}{*}{$\begin{array}{l}\text { Endometriosis treatments } \\
\text { (life time) }\end{array}$} & Pain killers & 410 (96.93) \\
\hline & $\begin{array}{l}\text { Surgical } \\
\text { treatments }\end{array}$ & $394(93.14)$ \\
\hline & $\begin{array}{l}\text { Hormonal } \\
\text { medications }\end{array}$ & $368(87.00)$ \\
\hline & $\begin{array}{l}\text { Complementary } \\
\text { treatments }\end{array}$ & $208(49.17)$ \\
\hline & Hormonal IUD & 175 (41.37) \\
\hline & Psychologist & $120(28.37)$ \\
\hline & Nutritionist & $95(22.46)$ \\
\hline & Physiotherapist & $72(17.02)$ \\
\hline & Sexual therapist & $15(3.55)$ \\
\hline & Other & 48 (11.35) \\
\hline \multirow{5}{*}{$\begin{array}{l}\text { Times presented to emergency } \\
\text { department due to endometriosis }\end{array}$} & Never & $165(39.01)$ \\
\hline & $1-2$ & $118(27.90)$ \\
\hline & $3-4$ & $55(13.00)$ \\
\hline & $5-10$ & $44(10.40)$ \\
\hline & More than 10 & $41(9.69)$ \\
\hline \multirow[t]{2}{*}{ Hysterectomy due to endometriosis } & No & 376 (88.89) \\
\hline & Yes & $47(11.11)$ \\
\hline
\end{tabular}

${ }^{\mathrm{a}}$ Mean $\pm S D$

${ }^{\mathrm{b}}$ Participants were asked to tick all that apply 
Table 2 Concurrent validity correlations of the 'last 12 months' EIQ dimensions with the EHP-5 scales $(n=423)$

\begin{tabular}{llll}
\hline EIQ (last 12 months) & EHP-5 & Number & Pearson Correlation $^{a}$ \\
\hline Physical-psychosocial & EHP-5 (score from 5 core items) & 412 & .80 \\
Physical & Pain & 407 & .66 \\
Psychological & Q2,3, \& 5 of the core questionnaire ${ }^{\text {b }}$ & 409 & .75 \\
Social & Social support & 402 & .64 \\
Sexual & Intercourse & 363 & .71 \\
Fertility & Infertility & 348 & .66 \\
Employment & Work & 360 & .66 \\
\hline
\end{tabular}

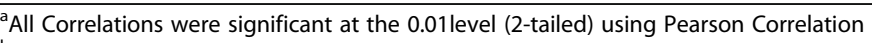

${ }^{\mathrm{b}}$ Control \& powerlessness, emotional wellbeing and self-image

4. The dimensions were scored on a scale from 0 (minimum possible impact), to 100 (maximum possible impact) as measured by the EIQ.

The EIQ scores for the sample as a whole, and the distribution of the scores are reported in Table 3. At each recall period, and also over a total of three recall periods, the highest impact of endometriosis was on fertility followed by the physical-psychosocial dimension, and the lowest impact was on the lifestyle dimension.

\section{Completion time of the EIQ}

The estimated completion time for the 66 item EIQ was 4.8-31.5 minutes with a mean \pm SD of $15.2 \pm 6.2$ minutes.

\section{Reliability}

The internal consistency reliability of the 63-item EIQ and the six dimensions was Cronbach's alpha 0.98 (Table 4). Results showed good reliability in all dimensions but the physical-psychosocial dimension had the highest and the lifestyle dimension had the lowest Cronbach's alpha for all three recall periods.

In the 63-item EIQ, all items correlated to total items at a level above 0.3 except for item numbered Q41, which correlated to total items at a level of 0.2. Cronbach's alpha for each recall period of the EIQ was 0.97 across the 63 items, indicating very good reliability. In each recall period, all items correlated to total items at a level above 0.3 except for two items, which correlated to total items at a level of 0.2. Within each dimension in each recall period, all items correlated to total items at a level above 0.3 .

Results of the inter-scale correlation matrix is shown in Table 5. Only responders who answered for both dimensions were included. All correlations were positive and statistically significant and there were high correlations between most dimensions at all recall periods.

\section{Test-retest reliability (stability)}

Test retest reliability using intra-class correlation (ICC) was conducted in 40 out of $70(60 \%)$ respondents who completed the second test after a two-week interval using the EIQ paper version. The results showed a statistically significant ICC between all dimensions at times one and 2, ranging from $0.88-0.99$. The results indicate that the EIQ has very good test-retest reliability.

\section{Discussion}

This study shows that the EIQ is a valid, reliable tool to measure the impact of endometriosis on women's lives with a long-term view. Endometriosis is a chronic disease as symptoms may continue despite seemingly adequate treatment [30]. Considering its recurring nature, there are some impacts that could be missed by only looking at the last four weeks. For example, current questionnaires are not able to measure the impacts on a woman who lost her sexual-intimate relationship or who was not able to complete studies and/or work goals, loss of job or promotion opportunities, or addressed her regrets from living with endometriosis. These impacts were revealed during our earlier qualitative study [17] and are supported by others [31, 32]. The EIQ is the first questionnaire to measure multi-dimensional impacts with a long-term view.

Validation of a scale involves the collection of empirical evidence concerning its use $^{26}$. Similar to the EIQ, the ETSQ [12] and the EPBD [13] were developed from focus group discussions and interviews with patients. Items of the EHP-30 were generated based on open-ended exploratory interviews with 25 women with endometriosis [10]. The process used to validate the EIQ was to some extent similar to the one employed for the ECQ [14], however the development processes were different.

Compared with the EHP-30 [10], the EIQ has two new subscales of education and lifestyle, whilst the EHP-30 has subscales of relationship with children, medical professionals, and treatment. Little is known about the impacts of endometriosis on lifestyle but negative impacts were reported during our earlier study [17]. Future studies should be conducted to measure the impact of endometriosis on lifestyle, as well as education and 
Table 3 Descriptive statistics of the EIQ dimension scoring

\begin{tabular}{|c|c|c|c|c|}
\hline EIQ dimensions & Last 12 months & 1 to 5 years ago & More than 5 years ago & Total three recall periods \\
\hline \multicolumn{5}{|c|}{ Physical-Psychosocial } \\
\hline Mean \pm SD & $62.69 \pm 27.25$ & $64.27 \pm 23.90$ & $56.12 \pm 24.90$ & $61.10 \pm 21.28$ \\
\hline Number ${ }^{a}$ & 412 & 418 & 401 & 390 \\
\hline Minimum (\%) & $.00(1.9)$ & $.00(1.4)$ & $.00(.9)$ & $6.31(.9)$ \\
\hline Maximum (\%) & $100.00(1.9)$ & $100.00(1.9)$ & $100.00(1.4)$ & $100.00(1.4)$ \\
\hline 25 & 44.70 & 50.00 & 38.11 & 46.81 \\
\hline Percentile 50 & 68.56 & 68.94 & 58.00 & 63.52 \\
\hline 75 & 85.61 & 82.58 & 75.38 & 77.28 \\
\hline \multicolumn{5}{|l|}{ Physical } \\
\hline Mean \pm SD & $62.46 \pm 27.38$ & $64.46 \pm 23.61$ & $58.93 \pm 24.50$ & $61.88 \pm 20.51$ \\
\hline Number & 407 & 416 & 400 & 384 \\
\hline Minimum (\%) & $.00(2.6)$ & $.00(2.1)$ & $.00(.9)$ & $8.97(.2)$ \\
\hline Maximum (\%) & $100.00(4.3)$ & $100.00(4.0)$ & $100.00(3.5)$ & $100.00(1.4)$ \\
\hline 25 & 46.15 & 51.92 & 40.91 & 47.09 \\
\hline Percentile 50 & 68.75 & 67.31 & 61.54 & 63.46 \\
\hline 75 & 84.62 & 81.25 & 76.92 & 76.28 \\
\hline \multicolumn{5}{|l|}{ Psychological } \\
\hline Mean \pm SD & $65.00 \pm 27.89$ & $66.21 \pm 25.07$ & $57.26 \pm 27.31$ & $62.76 \pm 22.89$ \\
\hline Number & 409 & 416 & 389 & 375 \\
\hline Minimum (\%) & $.00(1.9)$ & $.00(2.4)$ & $.00(3.5)$ & $1.56(.2)$ \\
\hline Maximum (\%) & $100.00(4.0)$ & 100.00 (3.8) & $100.00(3.3)$ & $100.00(1.7)$ \\
\hline 25 & 48.44 & 50.00 & 39.06 & 46.15 \\
\hline Percentile 50 & 71.88 & 72.60 & 59.38 & 67.19 \\
\hline 75 & 87.50 & 84.38 & 78.59 & 79.69 \\
\hline \multicolumn{5}{|l|}{ Social } \\
\hline Mean \pm SD & $54.81 \pm 34.89$ & $56.01 \pm 32.20$ & $47.23 \pm 32.67$ & $52.44 \pm 29.09$ \\
\hline Number & 402 & 407 & 373 & 352 \\
\hline Minimum (\%) & $.00(11.3)$ & $.00(8.5)$ & .00 (11.6) & $.00(4.3)$ \\
\hline Maximum (\%) & $100.00(16.8)$ & $100.00(13.9)$ & $100.00(10.6)$ & $100.00(5.9)$ \\
\hline 25 & 25.00 & 31.25 & 18.75 & 29.17 \\
\hline Percentile 50 & 62.50 & 56.25 & 43.75 & 54.17 \\
\hline 75 & 87.50 & 81.25 & 75.00 & 76.56 \\
\hline \multicolumn{5}{|l|}{ Sexual } \\
\hline Mean \pm SD & $47.24 \pm 28.65$ & $47.87 \pm 27.93$ & $40.88 \pm 29.89$ & $45.53 \pm 26.77$ \\
\hline Number & 375 & 381 & 343 & 320 \\
\hline Minimum (\%) & $.00(3.5)$ & $.00(3.8)$ & $.00(1.9)$ & $.00(.2)$ \\
\hline Maximum (\%) & $100.00(5.4)$ & 100.00 (3.8) & $100.00(1.9)$ & $100.00(2.4)$ \\
\hline 25 & 25.00 & 25.00 & 44.70 & 22.92 \\
\hline Percentile 50 & 50.00 & 46.43 & 68.56 & 44.05 \\
\hline 75 & 67.86 & 71.43 & 85.61 & 67.86 \\
\hline \multicolumn{5}{|l|}{ Fertility } \\
\hline Mean \pm SD & $70.23 \pm 37.59$ & $67.78 \pm 36.86$ & $58.24 \pm 38.90$ & $65.28 \pm 32.70$ \\
\hline Number & 391 & 390 & 347 & 323 \\
\hline Minimum (\%) & $.00(13.2)$ & $.00(11.3)$ & $.00(14.7)$ & $.00(4.0)$ \\
\hline
\end{tabular}


Table 3 Descriptive statistics of the EIQ dimension scoring (Continued)

\begin{tabular}{|c|c|c|c|c|}
\hline EIQ dimensions & Last 12 months & 1 to 5 years ago & More than 5 years ago & Total three recall periods \\
\hline Maximum (\%) & $100.00(46.1)$ & $100.00(41.1)$ & $100.00(27.0)$ & $100.00(18.9)$ \\
\hline 25 & 37.50 & 37.50 & 25.00 & 33.33 \\
\hline Percentile 50 & 91.67 & 83.33 & 66.67 & 75.00 \\
\hline 75 & 100.00 & 100.00 & 100.00 & 97.22 \\
\hline \multicolumn{5}{|l|}{ Employment } \\
\hline Mean \pm SD & $43.89 \pm 34.77$ & $43.66 \pm 32.78$ & $35.24 \pm 32.40$ & $41.04 \pm 30.42$ \\
\hline Number & 385 & 392 & 357 & 334 \\
\hline Minimum (\%) & $.00(10.2)$ & $.00(6.4)$ & $.00(11.3)$ & $.00(2.4)$ \\
\hline Maximum (\%) & $100.00(9.0)$ & $100.00(6.9)$ & $100.00(5.2)$ & $100.00(3.5)$ \\
\hline 25 & 11.36 & 15.91 & 8.71 & 14.20 \\
\hline Percentile 50 & 36.36 & 34.69 & 25.00 & 32.95 \\
\hline 75 & 75.00 & 72.67 & 60.56 & 64.58 \\
\hline \multicolumn{5}{|l|}{ Educational } \\
\hline Mean \pm SD & $46.61 \pm 39.32$ & $45.48 \pm 35.76$ & $43.99 \pm 33.71$ & $43.78 \pm 31.28$ \\
\hline Number & 173 & 206 & 241 & 149 \\
\hline Minimum (\%) & $.00(10.2)$ & $.00(8.5)$ & $.00(6.6)$ & $.00(2.4)$ \\
\hline Maximum (\%) & $100.00(7.1)$ & $100.00(7.1)$ & $100.00(6.1)$ & $100.00(2.4)$ \\
\hline 25 & 2.08 & 8.33 & 12.50 & 16.67 \\
\hline Percentile 50 & 45.83 & 43.75 & 37.50 & 38.89 \\
\hline 75 & 83.33 & 79.17 & 75.00 & 70.83 \\
\hline \multicolumn{5}{|l|}{ Lifestyle } \\
\hline Mean \pm SD & $16.54 \pm 23.88$ & $20.48 \pm 26.78$ & $20.75 \pm 28.76$ & $19.43 \pm 24.44$ \\
\hline Number & 391 & 397 & 367 & 342 \\
\hline Minimum (\%) & $.00(46.6)$ & $.00(43.0)$ & $.00(42.6)$ & $.00(29.8)$ \\
\hline Maximum (\%) & $100.00(2.4)$ & $100.00(2.8)$ & 100.00 (3.5) & $100.00(1.7)$ \\
\hline 25 & .00 & .00 & .00 & .00 \\
\hline Percentile 50 & .00 & 8.33 & 8.33 & 8.33 \\
\hline 75 & 25.00 & 33.33 & 33.33 & 33.33 \\
\hline
\end{tabular}

${ }^{a}$ Number of responders for whom that dimension at that recall period was applicable. Regarding the total scores, if responders skipped one of the recall periods, the total score for that dimension was not calculated

The scores were calculated on a scale from 0-100; a higher score means a greater impact of endometriosis on that dimension of life. $0=$ Minimum impact of endometriosis as measured by the EIQ; $100=$ maximum possible impact of endometriosis as measured by the EIQ

Out of 423 responders, $26(6.1 \%)$ participants skipped items from the sexual dimension, $26(6.1 \%)$ participants skipped items from the employment dimension, $152(35.9 \%)$ participants skipped items from the education dimension, and $8(1.9 \%)$ participants skipped items from the fertility and lifestyle dimensions

work which extend beyond time off and lost productivity addressed in previous studies $[5,8]$.

The demographic and medical characteristics of the responders in this study are consistent with endometriosis patients in previous research, increasing the generalizability of results. In a multinational study [5], 745 participants had a mean age of 32.5 years and a mean delay in diagnosis of 6.7 years, similar to the mean age (32.6) and delay (8.3) in this study. In an online survey most of 8008 patient (from China, France and Russia) were diagnosed within five years [33]. Thirty-eight percent of EIQ responders had delayed fertility, consistent with the infertility rate of $37 \%$ among 6,146 European patients [34] and 42.5\% among 7,020 US patients [35]. Eleven percent had a hysterectomy because of endometriosis, which is within the range of $8-29 \%$ reported by others [36].

The self-reporting characteristic of the EIQ has pros and cons. Sensitive information is more frequently and accurately reported in self-administered modes than when interviewers ask the questions [37]. However, limitations related to reporting and recall errors may apply because of the self-reported and retrospective nature of the EIQ. Questionnaire developers can overestimate people's ability to recall past events [20]. However, life time recall period has been used previously with satisfactory psychometric characteristics [14]. The decision to have three recall periods was based on focus group 
Table 4 Internal consistency of the 63-item EIQ and its dimensions

\begin{tabular}{llllll}
\hline & Number $^{\text {a }}$ & last 12 months & 1 to 5 years ago & more than 5 years ago" & Total three recall periods \\
\hline ElQ total & 423 & .97 (63 items) & .97 & .97 & $.98(189$ items) \\
Physical-psychosocial & 423 & .97 (33 items) & .96 & .95 & .98 (99 items) \\
Physical & 423 & .92 (13 items) & .90 & .90 & .94 (39 items) \\
psychological & 423 & .95 (16 items) & .93 & .92 & .96 (48 items) \\
Social & 423 & .91 (4 items) & .90 & .88 & .93 (12 items) \\
Sexual & 397 & .84 (7 items) & .85 & .86 & .93 (21 items) \\
Fertility & 415 & .73 (3 items) & .73 & .66 & .85 (9 items) \\
Employment & 397 & .94 (11 items) & .94 & .94 & .97 (33 items) \\
Educational & 271 & .93 (6 items) & .92 & .91 & .93 (18 items) \\
Lifestyle & 415 & .53 (3 items) & .57 & .62 & .84 (9items)
\end{tabular}

${ }^{a}$ Only responders who skipped all items of the dimension (all three recall periods) were omitted

discussions where women reported fluctuations in the impacts, variety of symptoms at different times, and differing perceptions of impacts based on their situation, desires, responsibilities and plans [17]. It is acknowledged that using multiple time frames might complicate the questionnaire and overburden respondents but the completion time of the EIQ was reasonable.

\section{Applications of the ElQ}

Use of disease-specific instruments in endometriosis research has been highlighted and preferred in recent literature reviews $[9,38]$. The EIQ, as a disease-specific questionnaire, could be used to provide detailed information on the multi-dimensional impacts of endometriosis in population health surveys, to compare different areas and stages of patients' lives or different management options. It could be used with all three recall periods or each period independently, because each has satisfactory validity and reliability. The total score for each dimension at three recall periods, for all dimensions at each recall period and the total impact score could be calculated. Combining the scores will depend

Table 5 Inter-scale correlation matrix for the last 12 months, 1 to 5 years ago, More than 5 years ago

\begin{tabular}{|c|c|c|c|c|c|c|}
\hline & Physical-psychosocial & Sexual & Fertility & Employment & Educational & Lifestyle \\
\hline Physical-Psychosocial & 1.00 & & & & & \\
\hline \multirow[t]{3}{*}{ Sexual } & $.63^{\mathrm{a}}$ & 1.00 & & & & \\
\hline & $.64^{\mathrm{b}}$ & & & & & \\
\hline & $.63^{c}$ & & & & & \\
\hline \multirow[t]{3}{*}{ Fertility } & $.41^{\mathrm{a}}$ & $.29^{\mathrm{a}}$ & 1.00 & & & \\
\hline & $.37^{b}$ & $.24^{\mathrm{b}}$ & & & & \\
\hline & $.47^{c}$ & $.33^{\mathrm{c}}$ & & & & \\
\hline \multirow[t]{3}{*}{ Employment } & $.74^{\mathrm{a}}$ & $.53^{\mathrm{a}}$ & $.31^{\mathrm{a}}$ & 1.00 & & \\
\hline & $.72^{\mathrm{b}}$ & $.54^{\mathrm{b}}$ & $.24^{\mathrm{b}}$ & & & \\
\hline & $.70^{c}$ & $.55^{c}$ & $.35^{c}$ & & & \\
\hline \multirow[t]{3}{*}{ Educational } & $.59^{\mathrm{a}}$ & $.43^{\mathrm{a}}$ & $.16^{\mathrm{a}}$ & $.72^{\mathrm{a}}$ & 1.00 & \\
\hline & $.60^{\mathrm{b}}$ & $.47^{\mathrm{b}}$ & $.20^{\mathrm{b}}$ & $.69^{b}$ & & \\
\hline & $.62^{c}$ & $.45^{\mathrm{c}}$ & $.27^{\mathrm{c}}$ & $.70^{c}$ & & \\
\hline \multirow[t]{3}{*}{ Lifestyle } & $.37^{\mathrm{a}}$ & $.32^{\mathrm{a}}$ & $.13^{\mathrm{a}}$ & $.31^{\mathrm{a}}$ & $.30^{\mathrm{a}}$ & 1.00 \\
\hline & $.38^{\mathrm{b}}$ & $.28^{\mathrm{b}}$ & $.13^{\mathrm{b}}$ & $.31^{\mathrm{b}}$ & $.33^{b}$ & \\
\hline & $.48^{c}$ & $.44^{c}$ & $.17^{\mathrm{c}}$ & $.43^{\mathrm{c}}$ & $.32^{c}$ & \\
\hline
\end{tabular}

Pearson correlation coefficient ( $r$ ) was evaluated

aLast 12 months: All Correlations were significant at the 0.01 level (2-tailed) except for fertility-education and fertility-lifestyle, which were significant at the 0.05 level (2-tailed)

${ }^{\mathrm{b}} 1$ to 5 years ago: All correlations were significant at the 0.01 level (2-tailed) except for fertility-lifestyle, which was significant at the 0.05 level (2-tailed)

${ }^{\mathrm{c}}$ More than 5 years ago: All correlations were significant at the 0.01 level (2-tailed) 
on the research objectives. Using the recall period of 'last 12 months', could be used in clinical trials and to investigate outcomes. It could be useful to guide development of an individualized disease management plan, and could help patients to communicate with health professionals and contribute to such a plan. It could also be used as a burden-estimation or needs assessment tool to provide information for making health policy decisions to improve services.

\section{Strengths of this study}

The EIQ was developed from focus group discussions, along with an extensive literature review, which ensured that the items are relevant to patients from either tertiary care or the community. A sample of 423 , reflected 6.41 responders per item, is close to being a 'very good' sample size [39]. There were no missing data as most items were compulsory in the online EIQ, but even those who answered the paper version for the test-retest did not miss any questions. The online questionnaire facilitated access to women within and beyond Australia, which was time and expense-saving.

\section{Limitations of this study}

Non-probability sampling decreases the ability to generalize results. Dissemination of the study link was focused inside Australia and $74 \%$ of responders to the online EIQ were born in Australia. Therefore, the applicability to Australian women with different characteristics to the participants, and non-Australians might be limited. Limitations related to reporting and recall errors may apply. As a web-based survey was used, the generalizibility of the results is restricted to those who are keyboard and Internet literate [40]. In addition, the current study did not collect clinical information regarding the severity of endometriosis lesions and the existence of comorbidities, such as mood disorders, obesity, musculoskeletal and neuropathic sources of pain, and patients undergoing treatment with psychotropic drugs that could also contribute to symptoms, and it is acknowledged that not knowing these clinical characteristics of the sample could limit the generalizability of the findings.

\section{Conclusions}

The EIQ has been developed and validated to measure the impacts of endometriosis on different aspects of women's lives with a long-term view. It can be used by researchers and clinicians to provide a better understanding of the impact of endometriosis on different aspects of life over time, and to meet the needs of women living with this condition. We recommend additional studies to establish stronger psychometric properties including known-groups validity and sensitivity to change for the 'last 12 months' section. Further validity evidence is also recommended in clinically relevant subgroups of endometriosis patients, such as women presenting for fertility evaluations versus women presenting with chronic pelvic pain, as well as endometriosis patients with the comorbid conditions. Studies in other countries and languages are recommended to make multinational studies possible.

\section{Additional file}

Additional file 1: 63-item ElQ. (PDF $428 \mathrm{~kb}$ )

\section{Abbreviations}

EIQ: Endometriosis Impact Questionnaire; HRQoL: Health-Related Quality of Life; QoL: Quality of life

\section{Acknowledgements \\ This article has been derived from a thesis submitted for the degree of Doctor of Philosophy at the Australian National University Medical School. We thank the participants for completing the questionnaire (EIQ) and helping us to make this study possible. We acknowledge the experts who provided valuable comments and feedback about the EIQ and many organizations and people who helped this study by disseminating the online questionnaire link.}

Ethical considerations and consent to participate

Approvals were obtained from the ACT Health Human Research Ethics Committee (ETH.6.13.155), and from the ANU Human Research Ethics Committee. The first page of the EIQ included a brief information form, and it was stated that "Completing this questionnaire is voluntary. By completing the questionnaire you are indicating your consent to participate in the study". Online EIQ was an anonymous web-based survey, and could be completed without a log in.

\section{Competing of interests}

The authors declare that they have no competing interests.

\section{Funding}

This research, including design of the study; collection, analysis, and interpretation of data; and the writing of the manuscript, has been supported by the Australian National University (ANU), School of Medicine within a PhD candidature.

\section{Availability of data and materials}

The datasets generated and analysed during the current study and more information regarding using the EIQ or scoring details will be available from the corresponding author on reasonable request.

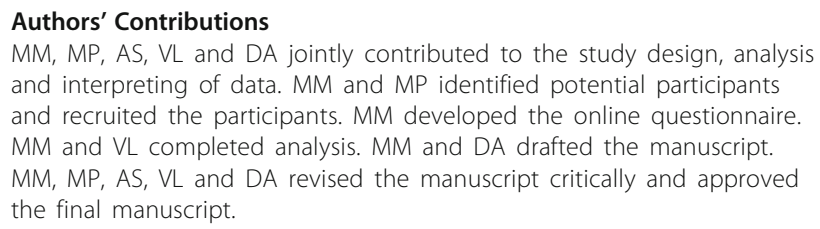
and interpreting of data. MM and MP identified potential participants and recruited the participants. MM developed the online questionnaire. $M M$ and $V L$ completed analysis. MM and DA drafted the manuscript. $M M, M P, A S, V L$ and $D A$ revised the manuscript critically and approved the final manuscript.

Consent for publication

Not applicable.

\section{Publisher's Note}

Springer Nature remains neutral with regard to jurisdictional claims in published maps and institutional affiliations. 


\section{Author details}

${ }^{1}$ Nursing and Midwifery Care Research Center, Mashhad University of Medical Sciences, Mashhad, Iran. 'Endometriosis Clinic, Canberra Hospital, Canberra, Australia. ${ }^{3}$ Griffith University, School of Medicine, Queensland, Australia. ${ }^{4}$ Yong Loo Lin School of Medicine, National University of Singapore, Singapore, Singapore.

Received: 23 July 2018 Accepted: 3 May 2019

Published online: 14 May 2019

\section{References}

1. Abbott J, Bowyer L, Finn M. Obstetrics \& gynaecology: an evidence-based guide. 2nd ed. Churchill Livingstone: Elsevier; 2014.

2. American Society for Reproductive Medicine. Treatment of pelvic pain associated with endometriosis: A committee opinion. Practice Committee of the American Society for Reproductive Medicine (ASRM). 2014;101(4):927-35.

3. Berek JS. Berek \& Novak's Gynecology. 15th ed: Lippincott Williams and Wilkins; 2012.

4. De Graaff AA, D'Hooghe TM, Dunselman GA, Dirksen CD, Hummelshoj L, Simoens S. The significant effect of endometriosis on physical, mental and social wellbeing: results from an international cross-sectional survey. Hum Reprod. 2013;28(10):2677-85. https://doi.org/10.1093/humrep/det284.

5. Nnoaham KE, Hummelshoj L, Webster P, D'Hooghe T, de Cicco NF, de Cicco NC, Jenkinson C, Kennedy SH, Zondervan KT. Impact of endometriosis on quality of life and work productivity: a multicenter study across ten countries. Fertil Steril. 2011;96(2):366-73 e368. https://doi.org/10.1016/j. fertnstert.2011.05.090.

6. Tripoli TM, Sato H, Sartori MG, de Araujo FF, Girao MJ, Schor E. Evaluation of quality of life and sexual satisfaction in women suffering from chronic pelvic pain with or without endometriosis. J Sex Med. 2011;8(2):497-503. https://doi.org/10.1111/j.1743-6109.2010.01976.x.

7. Sepulcri Rde P. doAmaral VF. Depressive symptoms, anxiety, and quality of life in women with pelvic endometriosis. Eur J Obstet Gynecol Reprod Biol. 2009;142(1):53-6. https://doi.org/10.1016/j.ejogrb.2008.09.003.

8. Simoens S, Dunselman G, Dirksen C, Hummelshoj L, Bokor A, Brandes I, Brodszky V, Canis M, Colombo GL, DeLeire T, et al. The burden of endometriosis: costs and quality of life of women with endometriosis and treated in referral centres. Hum Reprod. 2012;27(5):1292-9. https://doi.org/ 10.1093/humrep/des073.

9. Jia S, Leng J, Shi J, Sun P, Lang J. Health-related quality of life in women with endometriosis: a systematic review. Journal of Ovarian Research. 2012;5:29.

10. Jones G, Kennedy S, Barnard A, Wong J, Jenkinson C. Development of an endometriosis quality-of-life instrument: The Endometriosis Health Profile30. Obstetrics and Gynecology. 2001;98(2):258-64. https://doi.org/10.1016/ s0029-7844(01)01433-8.

11. Jones G, Jenkinson C, Kennedy S. Development of the Short Form Endometriosis Health Profile Questionnaire: the EHP-5. Qual Life Res. 2004;13(3):695-704.

12. Deal LS, Williams VS, DiBenedetti DB, Fehnel SE. Development and psychometric evaluation of the Endometriosis Treatment Satisfaction Questionnaire. Qual Life Res. 2010;19(6):899-905. https://doi.org/10.1007/ s11136-010-9640-6.

13. Deal LS, DiBenedetti DB, Williams VS, Fehnel SE. The development and validation of the daily electronic Endometriosis Pain and Bleeding Diary. Health Qual Life Outcomes. 2010;8:64. https://doi.org/10.1186/1477-7525-8-64.

14. Dancet EA, Ameye L, Sermeus W, Welkenhuysen M, Nelen WL, Tully L, De Bie B, Veit J, Vedsted-Hansen $\mathrm{H}$, Zondervan KT. The ENDOCARE questionnaire (ECQ): a valid and reliable instrument to measure the patientcenteredness of endometriosis care in Europe. Hum Reprod. 2011;26(11): 2988-99. https://doi.org/10.1093/humrep/der277.

15. Ferrero S, Esposito F, Abbamonte LH, Anserini P, Remorgida V, Ragni N. O. Quality of sex life in women with endometriosis and deep dyspareunia. Fertil Steril. 2005;83(3):573-9. https://doi.org/10.1016/j.fertnstert.2004.07.973.

16. Fritzer $\mathrm{N}$, Haas D, Oppelt $\mathrm{P}$, Renner $\mathrm{S}$, Hornung D, Wolfler M, Ulrich U, Fischerlehner G, Sillem M, Hudelist G. More than just bad sex: sexual dysfunction and distress in patients with endometriosis. Eur J Obstet Gynecol Reprod Biol. 2013;169(2):392-6. https://doi.org/10.1016/j.ejogrb. 2013.04.001

17. Moradi M, Parker M, Sneddon A, Lopez V, Ellwood D. Impact of endometriosis on women's lives: a qualitative study. BMC Women's Health. 2014;14:123. https://doi.org/10.1186/1472-6874-14-123.
18. LoBiondo-Wood G, Haber J. Nursing Research: Methods and Critical Appraisal for Evidence-Based Practice. 7th ed: MOSBY Elsevier; 2010.

19. DeVellis RF. Scale Development: Theory and Applications. 3rd ed. SAGE publications; 2012

20. Streiner DL, Norman GR. Health Measurement Scales: A practical guide to their development and use. 4th ed. Oxford University Press; 2008.

21. Grove S, Burns N, Gray J. The practice of nursing research: appraisal, synthesis, and generation of evidence. 7th ed. Saunders Elsevier; 2013.

22. ReadabilityFormulas.com, free readability tools to check for reading levels, reading assessment and reading grade levels. [readabilityformulas website]. http://www.readabilityformulas.com/ . Accessed 21 July 2018.

23. Grant JS, Davis LL. Focus on questionnaire methods, selection and use of content experts for instrument development. Res Nurs Health. 1997;20(3):269-74.

24. Davis LL. Instrument review: Getting the most from a panel of experts. Applied Nursing Research. 1992;5(4):194-7.

25. Polit DF, Beck CT. The content validity index: are you sure you know what's being reported? Critique and recommendations. Res Nurs Health. 2006; 29(5):489-97. https://doi.org/10.1002/nur.20147.

26. Pallant J. SPSS Survival Manual: A step by step guide to data analysis using the SPSS program. 4th ed: Allen \& Unwin; 2011.

27. Gaskin CJ, Happell B. On exploratory factor analysis: a review of recent evidence, an assessment of current practice, and recommendations for future use. Int J Nurs Stud. 2014;51(3):511-21. https://doi.org/10.1016/j. ijnurstu.2013.10.005.

28. Matsunaga M. How to factor-analysis you data right: Do's, Don'ts, and How To's. Int J Psychol Res. 2011;3(1):97-110.

29. DeVon HA, Block ME, Moyle-Wright P, Ernst DM, Hayden SJ, Lazzara DJ, Savoy SM, Kostas-Polston E. A Psychometric Toolbox for Testing Validity and Reliability. J Nurs Sch. 2007;39(2):155-64.

30. D'Hooghe T, Hummelshoj L. Multidisciplinary centres/networks of excellence for endometriosis management and research: a proposal. Hum Reprod. 2006;21:2743-8.

31. Jones $\mathrm{G}$, Jenkinson C, Kennedy S. The impact of endometriosis upon quality of life: a qualitative analysis. J Psychosom Obstet Gynaecol. 2004;25(2):123-33.

32. Denny E. Women's experience of endometriosis. J Adv Nurs. 2004;46(6):6418. https://doi.org/10.1111/j.1365-2648.2004.03055.x

33. Chapron C, Santulli P, Cabri P. The pain and daily consequences of living with endometriosis: a qualitative online survey of women in China, France and Russia. Journal of Endometriosis and Pelvic Pain Disorders. 2016;7(3):89-94. https://doi.org/10.5301/je.5000222.

34. Eisenberg VH, Weil C, Chodick G, Shalev V. Epidemiology of endometriosis: a large population-based database study from a healthcare provider with 2 million members. BJOG. 2018;125(1):55-62. https://doi.org/10.1111/14710528.14711

35. Ballweg ML. Impact of endometriosis on women's health: comparative historical data show that the earlier the onset, the more severe the disease. Best Pract Res Clin Obstet Gynaecol. 2004;18(2):201-18. https://doi.org/10. 1016/j.bpobgyn.2004.01.003.

36. Longinotti MK, Jacobson GF, Hung YY, Learman LA. Probability of hysterectomy after endometrial ablation. Obstet Gynecol. 2008;112(6):1214-1220. DECEMBER.

37. Floyd J, Jr F. Survey research methods. 4th ed: SAGE publication; 2009.

38. Culley L, Law C, Hudson N, Denny E, Mitchell H, Baumgarten M, RaineFenning N. The social and psychological impact of endometriosis on women's lives: a critical narrative review. Hum. Reprod. 2013;19(6):625-39. https://doi.org/10.1093/humupd/dmt027.

39. MacCallum RC, Widaman KF, Zhang S, Hong S. Sample size in factor analysis. Psychological Methods. 1999;4:84-99.

40. Wyatt JC. When to Use Web-based Surveys. J Am Med Inform Assoc. 2000;7(4):426-9. 